\title{
REVIEW
}

\section{Understanding CD30 biology and therapeutic targeting: a historical perspective providing insight into future directions}

\author{
CA van der Weyden ${ }^{1}$, SA Pileri ${ }^{2,3}$, AL Feldman $^{4}$, J Whisstock ${ }^{5}$ and HM Prince ${ }^{1,6,7}$
}

\begin{abstract}
CD30 is a member of the tumor necrosis factor receptor superfamily. It is characteristically expressed in certain hematopoietic malignancies, including anaplastic large cell lymphoma and Hodgkin lymphoma, among others. The variable expression of CD30 on both normal and malignant lymphoid cells has focused research efforts on understanding the pathogenesis of CD30 upregulation, its contribution to lymphomagenesis through anti-apoptotic mechanisms, and its effect on cell survival. Given the restriction of $\mathrm{CD} 30$ to certain tumor types, the logical extension of this has been to attempt to exploit it as a therapeutic target. The efficacy of naked anti-CD30 antibodies in practice was, however, modest. Moreover, combinations with bacterial toxins and radioimmunoconjugates have also had limited success. The development of the antibody-drug compound brentuximab vedotin (BV), however, has rejuvenated interest in CD30 as a tumor target. Phase I and II clinical trials in Hodgkin lymphoma, peripheral T-cell lymphoma, cutaneous T cell lymphoma, and even CD30-expressing B-cell lymphomas, have shown the compound is well tolerated, but more importantly, able to deliver meaningful disease control even in patients with multiply relapsed or refractory disease. FDA approval has been granted for its use in relapsed Hodgkin lymphoma and systemic anaplastic large cell lymphoma. A recent phase III trial of BV in cutaneous T-cell lymphoma has confirmed its superiority to standard of care therapies. In this manuscript, we explore the history of CD30 as a tumor marker and as a therapeutic target, both in the laboratory and in the clinic, with a view to understanding future avenues for further study.
\end{abstract}

Blood Cancer Journal (2017) 7, e603; doi:10.1038/bcj.2017.85; published online 8 September 2017

\section{CD30 MOLECULE-CLONING AND CHARACTERIZATION OF TISSUE EXPRESSION}

CD30, also known as Ki-1or TNFRSF8, was first identified in 1982 using a monoclonal antibody (mAb) derived from a Hodgkin lymphoma (HL) cell line. ${ }^{1,2}$ The CD30 molecule was subsequently cloned and characterized as a $120 \mathrm{kD}$ transmembrane glycoprotein receptor belonging to the tumor necrosis factor receptor (TNFR) superfamily, with intracellular, trans-membrane and extracellular domains. ${ }^{3,4}$ Sequence similarity between CD30 and other TNFR molecules is limited to the extracellular components; in $\mathrm{CD} 30$, these are comprised of six cysteine-rich repeats. ${ }^{5}$ Further delineation of CD30 epitopes suggested the extracellular components adopt a flower-like configuration. ${ }^{6}$ Later structural studies on other TNFR-related molecules-alone and in complex with ligands - suggest that the extracellular cysteine-rich repeats most

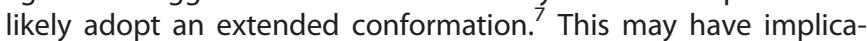
tions for antibody binding.

CD30 ligand (CD30L, also known as TNFSF8 or CD153) is a membrane-bound cytokine with sequence homology to other members of the tumor necrosis factor (TNF) family. ${ }^{4} \mathrm{CD} 30 \mathrm{~L}$ can be detected in vitro on a subset of activated lymphocytes, histiocytes and granulocytes, and has been demonstrated on Reed-Sternberg cells and some T-cell lymphomas, although not consistently on anaplastic large cell lymphomas (ALCL). ${ }^{8-12}$ Additionally, an $88 \mathrm{kD}$ form of soluble $\mathrm{CD} 30$ ( $\mathrm{sCD} 30)$ can be detected in vivo in inflammatory states and CD30-positive hematologic malignancies, and is presumed to represent a cleavage by-product of the extracellular portion of CD30. ${ }^{13}$

CD30 is expressed on a small subset of activated $T$ and $B$ lymphocytes, and a variety of lymphoid neoplasms, with the highest expression in classical HL and ALCL. It has been demonstrated with variable expression and intensity in some cases of peripheral T-cell lymphoma, not otherwise specified (PTCL-NOS); adult T-cell leukemia/lymphoma; cutaneous T-cell lymphoma (CTCL); extra-nodal NK-T-cell lymphoma; and a variety of B-cell non-HLs, including diffuse large B-cell lymphoma, particularly EBV-positive diffuse large B-cell lymphoma. ${ }^{8,14-22}$ Neoplastic mast cells in advanced systemic mastocytosis have also been shown to be CD30-positive. ${ }^{23,24}$ Less commonly, CD30 expression is seen in certain non-hematopoietic malignancies, including germ cell tumors and testicular embryonal carcinomas. ${ }^{15}$

The BerH2 antibody is used for routine assessment of CD30 expression in tissue specimens, with good correlation between immunohistochemical protein expression and specific mRNA levels. ${ }^{25,26} \mathrm{Kim}$ et al. reported the use of multi-spectral imaging in their study of brentuximab vedotin (BV) in $C T C L$, quantifying CD30 expression in biopsies otherwise designated CD30-negative by immunohistochemistry $(\mathrm{IHC})$, thus defining a 'low-level positive' tumor group. Double antibody-conjugate techniques were employed to assess whether $\mathrm{CD} 30$ expression was

\footnotetext{
${ }^{1}$ Department of Haematology, Peter McCallum Cancer Centre, Melbourne, Victoria, Australia; ${ }^{2}$ Haematopathology Unit, European Institute of Oncology, Milan, Italy; ${ }^{3}$ Bologna University School of Medicine, Bologna, Italy; ${ }^{4}$ Department of Laboratory Medicine and Pathology, Mayo Clinic, Rochester, MN, USA; ${ }^{5}$ ARC Centre of Excellence in Advanced Molecular Imaging, Monash University, Clayton, Victoria, Australia; ${ }^{6}$ Epworth Healthcare, Melbourne, Victoria, Australia and ${ }^{7}$ Sir Peter MacCallum Department of Oncology, University of Melbourne, Parkville, Victoria, Australia. Correspondence: Professor HM Prince, Peter MacCallum Cancer Centre, Locked Bag 1 A'Beckett Street, Melbourne, Victoria 8006, Australia.
} 
representative of tumor, or of tumor-infiltrating inflammatory cells such as cytotoxic T-lymphocytes or macrophages. ${ }^{27}$ While these techniques are not widely available, these results raise interesting questions about the contribution of the tumor microenvironment to lymphomagenesis, the specificity of CD30 as a treatment target, and how to best assess patient suitability for anti-CD30 therapies.

While CD30-positivity in ALCL is defined as tumor cell expression of $75 \%$ or higher, diagnostic cut-offs for other tumor types have not been universally agreed upon. In mycosis fungoides (MF), for example, CD30 positivity is much less than in $\mathrm{ALCL}$, with one group reporting median epidermal staining of $14 \%$ in non-transformed cases, with higher expression levels in more advanced stages and large-cell transformation. ${ }^{28}$ It is a matter of debate whether CD30 expression levels permit stratification of expected responses to anti-CD30 therapies.

\section{ROLE OF CD30 IN HEALTH AND DISEASE}

Given the relative restriction of CD30 expression, early studies sought to characterize the driving factors behind CD30 upregulation in normal tissue. Initial studies showed that CD30 expression on lymphocytes could be induced by in vitro antigenic stimulation by mitogens or viruses, especially HIV, EBV and HTLV-1. ${ }^{29}$ Subsequent studies demonstrated that CD30 expression was not uniform across all activated lymphocytes, instead being limited to subpopulations of $\mathrm{CD}^{+} / \mathrm{CD} 45 \mathrm{RO}^{+}$and $\mathrm{CD} 8^{+} \mathrm{T}$ cells in lymph nodes and the thymic medulla. CD30 expression appears higher in CD4+ and CD8+ cells producing a Th2-type cytokine response, ${ }^{4,18,30-32}$ although subsequent studies have also demonstrated CD30 expression on Th0 and Th1-specific cells. ${ }^{33}$ Additionally, building on the work of Stein et al., Catoretti et al. demonstrated that CD30 expression in B-lymphocytes is restricted to a minority population of stimulated B immunoblasts located at the edge of the germinal center and the extrafollicular region, with co-expression of markers of acute activation. ${ }^{14,34,35}$

CD30 knockout mice have been studied in an attempt to understand the role of $\mathrm{CD} 30$ expression, albeit with somewhat conflicting results. Amakawa et al. demonstrated that the development and maintenance of memory $T$ cells, as well as T-helper cell-dependent B-cell class-switching, were not impaired in response to mitogenic stimulation in their CD30 mutant mice, which the researchers felt argued against CD30 being involved in maintenance of the immune response. The researchers additionally found that CD30 mutant mice had increased thymic volume and increased numbers of circulating double-antigen positive T cells, suggesting a role for CD30 in negative selection in the thymus, although this has not been confirmed by later researchers. ${ }^{36}$ Subsequent studies have, however, reported contrasting results to these earlier conclusions. Gaspal et al. demonstrated that secondary antibody production-a process dependent on follicular $T$ cells-was impaired in mice deficient in CD30, with loss of a sustained germinal center response, even though the primary response to antigen stimulation was normal, a result recapitulated in $\mathrm{CD} 30-\mathrm{OX} 40$ co-deficient mice. These results were replicated by Kennedy et al. ${ }^{37,38}$ Overall, these findings underscore a role for CD30 in immune surveillance and cross-talk between $B$ and $T$ cells.

Subsequent studies have assessed the effects of CD30 stimulation in order to understand the cell signaling pathways linked to CD30. Epitope stimulation of CD30 results in receptor trimerization and signal transduction via the recruitment of TNFRassociated factor (TRAF) and TRAF-binding proteins, generating a signaling complex. ${ }^{5,39}$ TRAF2, as well as TRAF1 and TRAF5, have all been implicated in the signaling process. Downstream effects of CD30 stimulation are mediated in part by nuclear factor kappa B (NFkB), as well as by mitogen-activated protein kinase/extracellular signal-regulated kinase pathways, as outlined in Figure 1.40-44

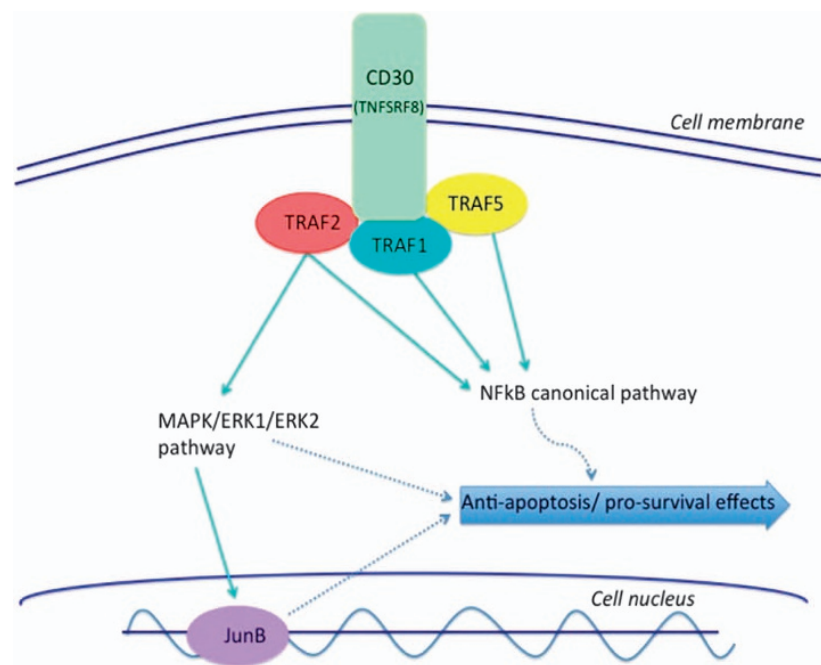

Figure 1. CD30 mediates its effects through a number of diverse signaling pathways, which in concert confer a survival benefit to the cells on which CD30 is upregulated. Stimulation of the CD30 molecule results in trimerization and signal mediation through tumor necrosis factor receptor-associated proteins (TRAF), in particular TRAF2, but also TRAF1 and TRAF5, to stimulate the nuclear factor-kappa B (NFkB) pathway. In addition to this, CD30 ligation also signals through the mitogen-activated protein kinase (MAPK) pathways, including ERK1 and ERK2, which have diverse anti-apoptotic and pro-survival benefits in the neoplastic cell. There appears to be a positive feedback loop between the MAPK/ERK pathway and the nuclear transcription factor JunB, which not only contributes to cell survival, but also upregulates CD30 expression.

The restricted expression of $C D 30$ suggests the possibility that CD30 plays a role in the development and propagation of $\mathrm{HL}$ and ALCL. However, defining if and how CD30 expression relates specifically to lymphomagenesis-rather than being merely a marker of cell of origin-has proven challenging. Certainly the finding that the NFkB and mitogen-activated protein kinase/ extracellular signal-regulated kinase pathways are integral to CD30-mediated signaling suggests that CD30 expression may confer a proliferative and anti-apoptotic benefit in neoplastic cells. ${ }^{44-46}$ Horie et al. proposed a link between CD30 overexpression and ligand-independent stimulation of the NFkB pathways in $\mathrm{HL}$ cells, underscoring a possible link between CD30 expression and tumor perpetuation. These findings were not replicated by Hirsch et al., who instead suggested that NFkB activation in $\mathrm{HL}$ is constitutive and unrelated to $\mathrm{CD} 30 .{ }^{47,48}$ In contrast, Watanabe et al. showed that CD30 upregulation in $\mathrm{HL}$ and ALCL cell lines might be linked by a self-perpetuating loop through the mitogen-activated protein kinase/extracellular signalregulated kinase pathway to the expression of JunB, a member of the activator protein (AP-1) transcription factor family, with diverse effects including a possible link to malignant transformation. ${ }^{49}$ Boddicker et al. demonstrated in ALCL cell lines that the transcription factor interferon regulatory factor-4 (IRF4) drives CD30 expression in a positive feedback loop involving NFkB. ${ }^{50}$ In addition to IRF4 and AP-1/Jun B, other groups have identified the Ets transcription family as being implicated in tumor cell CD30 upregulation. ${ }^{50-53}$

Leading on from this, additional studies sought to define the role of CD30 stimulation in lymphoma pathogenesis; however, interpretation of the results is hampered somewhat by the use of differing ligands between studies. Early studies assessed the effects of the CD30 cognate, CD30L, in different cell lines. CD30L binding showed pleiotropic effects in vitro, with activation and enhanced cytokine secretion in $\mathrm{HL}$ cells, but a pro-apoptotic effect in $\mathrm{ALCL}$ cells. ${ }^{54,55}$ Subsequent assessment of CD30 stimulation in 
$\mathrm{ALCL}$ and $\mathrm{HL}$ cell lines using the monoclonal antibody (mAb) Ki-1 also demonstrated a differential response, with decreased proliferation and increased apoptosis in ALCL cells, while $\mathrm{HL}$ cell lines were unaffected. ${ }^{48,56}$ Gene expression profiling studies confirmed a marked difference in gene transcription between the $\mathrm{HL}$ and $\mathrm{ALCL}$ cell lines in response to CD30 stimulation. ${ }^{48,57}$ Mir et al. suggested that the variable responses to CD30 stimulation in $\mathrm{HL}$ and $\mathrm{ALCL}$ cell lines might reflect the presence of a defective inhibitory protein in $\mathrm{HL}$, permitting constitutive NFkB signaling, as well as insensitivity to $\mathrm{CD} 30$-mediated pro-apoptotic signaling. ${ }^{56}$

Later work by Buchan and Al-Shamkani suggested that the pleiotropic effects of $\mathrm{CD} 30$ stimulation might be mediated through the activation of different regions in the cytoplasmic tail. This raises the question of whether the activation of different regions is cell-type or ligand specific, and therefore whether this differential effect can be harnessed clinically. ${ }^{45}$ Indeed, one of the difficulties in understanding the pleiotropic effects of CD30 stimulation extends from the fact that these studies were performed in variable cognates in tumor cell lines, without a concomitant clear explication of the effects of CD30 stimulation by CD30L in normal tissues. More importantly, while CD30L can be detected in $\mathrm{HL}$, it has not been as clearly demonstrated in $\mathrm{ALCL}$, and as such, it is ultimately unclear whether it can be assumed to contribute to lymphomagenesis in all CD30-expressing tumors.

\section{CD30 AS A TUMOR TARGET}

Given the overexpression of CD30 in certain lymphoma subtypes and some non-lymphoid neoplasms, it seems logical to exploit it as a therapeutic target.

\section{Monoclonal antibody monotherapy}

Preclinical studies. The development of humanized anti-CD30 mAbs paved the way for clinical trials of immunotherapy. Initial preclinical studies in the mid- to late 1990s used murine anti-CD30 mAbs, with reported improved disease-free survival rates in xenograft mice treated with M44 or HeFi-1, and, in a later study using HeFi-1, tumor growth arrest or regression in an $\mathrm{ALCL}$ xenograft model. ${ }^{58,59}$ Leading on from these studies, focus was directed to the creation of humanized mAbs, resulting in the development of SGN-30, a chimeric mouse-human antibody, and the fully humanized mAb 5F11 (MDX-060, or iratumumab).

Studies reported between 2002 and 2010 examined the effects of SGN-30 in HL and adult T-cell leukemia/lymphoma cell lines and mouse models. In contrast to earlier studies using non-humanized $\mathrm{mAb}$, investigators were able to demonstrate cellular growth arrest and DNA fragmentation in vitro in $\mathrm{HL}$ cell lines treated with SGN-30. Moreover, tumor regression and improved survival was observed in a mouse xenograft cohort. ${ }^{60-62}$ One explanation advanced for this unexpected response in $\mathrm{HL}$ was that SGN-30 itself promotes receptor cross-linking and multimerization, potentially promoting growth arrest and pro-apoptotic signaling. ${ }^{61}$

Similarly, 5F11 was able to promote cell growth arrest in CD30positive cell lines when receptor cross-linking occurred, enhancing antibody-dependent cell cytotoxicity. Tumor regression was seen in $\mathrm{HL}$ xenograft mouse models. ${ }^{63}$

Clinical studies. Based on promising results in preclinical studies, phase I and II trials of both SGN-30 and 5F11 were undertaken. However, the results of early phase studies did not seem to offer significant promise for the use of 'naked' anti-CD30 mAbs in practice.

The phase I trial of SGN-30 was conducted in 2002 and 2003, including 24 patients with relapsed or refractory HL or CD30positive non-HL. SGN-30 was administered weekly for six doses, and was well tolerated. Clinical benefits were modest, with six patients achieving stable disease, and one patient with primary cutaneous ALCL achieving a complete response (CR). ${ }^{64}$

A subsequent phase II trial of SGN-30 in patients with $\mathrm{HL}$ and ALCL used the same dosing schedule with doses of either $6 \mathrm{mg} / \mathrm{kg}$ or $12 \mathrm{mg} / \mathrm{kg}$; the regimen was again well tolerated. Clinical outcomes were, however, disappointing. Of the 38 patients with relapsed/refractory $\mathrm{HL}, 11$ patients achieved stable disease, while none achieved CR or partial responses (PR). In the ALCL cohort of 41 patients, two CR and five PR were attained. ${ }^{65}$

Duvic et al. reported phase II results for the use of SGN-30 in relapsed/refractory cutaneous ALCL and other CD30-positive lymphoproliferative disorders. In this study, objective responses were seen in 16 of 23 patients (70\%), with 10 patients achieving CR and six achieving PR. Overall clinical benefit rate was $87 \%$, and median duration of objective response was 84 days. There appeared to be a dose-response effect, with some patients achieving clinical responses at $12 \mathrm{mg} / \mathrm{kg}$ despite having minimal benefit at $4 \mathrm{mg} / \mathrm{kg}^{66}$

5F11 (MDX-060), a fully humanized anti-CD30 mAb, was the focus of a phase I/II trial in HL and systemic ALCL. Twenty-one patients were treated in the phase I cohort and 51 in the phase II cohort; of these patients, 25 achieved stable disease, two achieved PR and four achieved CR, with a median duration of response of less than 6 months in all groups. The investigators noted high rates of corticosteroid use in this study population, with 31 patients receiving steroids during treatment, including four patients with objective responses. ${ }^{67}$ Further clinical trials have not been pursued.

Immunoconjugates

Immunotoxins. Early studies of anti-CD30 immunoconjugates focused on immunotoxins, albeit with limited success. The BerH2-saporin anti-CD30 immunotoxin used a ribosomeinactivating protein type 1 (RIP-1), with demonstrable efficacy invitro and in animal studies. ${ }^{68,69}$ Later combinations included conjugates of BerH2 and other RIP-1s, the anti CD30Pseudomonas exotoxin A conjugate Ki-4 (scFv)-ETA', and the anti-CD30 ricin A-chain immunotoxin. ${ }^{70-73}$ However, the efficacy of these immunotoxins in humans was hampered by high rates of the development of anti-therapeutic antibodies, CD30 downregulation, or non-specific binding of the immunotoxin to soluble CD30. ${ }^{71,74}$

Radioimmunoconjugates. Anti-CD30 radioimmunoconjugates have shown mixed results in preclinical studies, with limited scope for clinical development. A conjugate of $\mathrm{Ki}-4$ and radiolabeled iodine (I-131) was tested in 22 patients with $\mathrm{HL}$, with one $C R$ and five $P R$, but had significant side effects, with seven patients experiencing grade 4 hematologic toxicity. ${ }^{75}$

Later combinations using Ki-4 and 5F11 antibodies with variable iodination showed high in vitro tumor cell specificity, but minimal efficacy in vivo in mouse models. ${ }^{76}$ The combination of HeFi-1 with either radiolabeled astatine (At-211) or yttrium (Y-90) showed preliminary efficacy in murine models; however, no clinical trials eventuated. ${ }^{77}$

Brentuximab vedotin. The development of a novel antibody-drug conjugate (ADC), BV (also referred to as SGN-35 or CAC10vcMMAE), seemed to overcome some of the problems seen with SGN-30. Brentuximab vedotin consists of the humanized $\lg _{1}$ mAb SGN-30, in combination with the antimitotic agent monomethylauristatin $\mathrm{E}(\mathrm{MMAE})$, joined by a cathepsin cleavable linker (valine-citrulline). ${ }^{78}$

Brentuximab vedotin acts through binding of the ADC to CD30positive cells, followed by receptor endocytosis and release of MMAE upon exposure to intracellular lysozymes. This results in inhibition of tubulin formation and cell apoptosis. Bystander cells 
may also be susceptible to effluxed MMAE, with at least one study demonstrating apoptotic induction in co-cultured CD30-negative tumor cells. ${ }^{79,80}$ Additionally, it seems that MMAE itself promotes T-cell expansion and activation, not only through enhanced antigen presentation, but also via a direct priming effect on dendritic cell maturation and differentiation. ${ }^{81}$

Brentuximab vedotin-preclinical studies. Preclinical studies confirmed efficacy of BV in vitro and in mouse models. Francisco et al. used $B V$ in $\mathrm{HL}$ and $\mathrm{ALCL}$ cell lines, demonstrating in vitro stability, and ADC selectivity for CD30-positive cells. More importantly, BV successfully induced cell cycle arrest and apoptosis. In xenograft mouse models, BV treatment resulted in partial tumor regression in an $\mathrm{HL}$ model and complete tumor regression in an ALCL model, with a significant difference in tumor responses when compared to the 'naked' antibody. These treatment responses held true in mouse models of both subcutaneous and disseminated ALCL. ${ }^{78}$

Following on from this, Maeda et al. demonstrated a growth inhibitory effect of both SGN-30 and SGN-35 in adult T-cell leukemia/lymphoma cell lines. More importantly, mouse models treated with SGN-35 showed tumor regression. ${ }^{60}$

Blatt et al. examined the effects of BV in CD30-positive systemic mastocytosis. The researchers confirmed CD30 expression in systemic mastocytosis cell lines, and demonstrated cell apoptosis and death in response to BV. Interestingly, BV exposure did not appear to increase the risk of histamine release, and, moreover, appeared to downregulate IgE-mediated manifestations of histamine release. ${ }^{23}$

Brentuximab vedotin-clinical studies. Based on the promising results of preclinical studies, a phase I trial of BV was conducted in 45 patients with relapsed/refractory CD30-positive hematologic malignancies, including 42 patients with $\mathrm{HL}$, two with systemic $A L C L$, and one with angioimmunoblastic T-cell lymphoma. The median number of prior therapies in this group was three (range one to seven), including 33 patients (73\%) who had undergone an autologous stem cell transplant (auSCT); 17 patients had objective responses, including $11 \mathrm{CR}$, with a median duration of response of 9.7 months. Tumor regression was seen in 36 of 42 patients ( $86 \%)$ evaluable for radiologic response. The main side effects were fatigue, nausea, diarrhea, neutropenia, and peripheral neuropathy, with the latter seen in 16 patients. The recommended phase 2 dose was $1.8 \mathrm{mg} / \mathrm{kg}^{82}$

Phase II and III studies using BV followed thereafter, as summarized in Table 1.

Pro et al. reported results for a cohort with relapsed/refractory systemic ALCL. 58 patients were dosed with $1.8 \mathrm{mg} / \mathrm{kg}$ every three weeks; 50 patients (86\%) achieved objective responses, including 33 patients attaining $C R$ and 17 patients attaining PR. The median duration of overall response was 12.6 months, and the median CR duration was 13.2 months. The most common grade 3 or 4 side effects included neutropenia, thrombocytopenia, and sensory neuropathy in $12 \%$ of patients. ${ }^{83}$

Younes et al. reported results for 102 patients with $\mathrm{HL}$ who had relapsed after auSCT. The objective response rate (ORR) was $75 \%$, with a CR rate of $34 \%$. Median duration of response was 6.7 months in all responders, and 20.5 months in those patients achieving CR. These findings are important given that the median number of prior treatments excluding auSCT was three, with a median time to relapse after transplant of 6.7 months, suggesting relatively chemo-refractory disease. Side effects were similar to those reported by Pro et al.; twenty patients discontinued therapy due to adverse events, predominantly sensory or motor neuropathies. ${ }^{84}$ A smaller study by Horwitz et al. in 35 patients with PTCL showed an ORR of $41 \%$, with eight patients achieving CR. While the median progression-free survival (PFS) was 6.7 months in patients with angioimmunoblastic T-cell lymphoma, median PFS was a disappointing 1.6 months in the PTCL-NOS subgroup. 85

In CTCL, phase II trials have been conducted in patients with Sezary syndrome and mycosis fungoides (MF), as well as in primary cutaneous ALCL and lymphomatoid papulosis. Kim et al. reported objective responses in 21 of 30 patients with either Sezary syndrome or MF, with seven patients having $>90 \%$ clearance of cutaneous disease. It is notable that clinical response was not limited to those patients with $>10 \%$ CD30 expression by IHC. ${ }^{27}$ Duvic et al. reported an ORR of $73 \%$ in their cohort of 48 patients, including CR in 17 patients. Mirroring the findings of Kim et al., responses were seen even in MF/Sezary syndrome patients with low CD30 expression, defined as $<10 \%$ by IHC. All 11 patients with either primary cutaneous $A L C L$ or lymphomatoid papulosis responded to $\mathrm{BV}$; however, the median duration of response in this group was only 26 weeks. ${ }^{86}$

Prince et al. have recently reported the results of a phase III trial in CTCL of BV versus physician's choice of either methotrexate or bexarotene. This study of 128 patients with CTCL included 97 patients with MF and 31 with primary cutaneous ALCL. The cut-off for CD30 positivity in this study was defined as $10 \%$ in at least one tumor sample; multiple biopsies could be submitted for central review, and not all biopsies had to meet this cut-off requirement. Primary endpoints were overall response rates of four months or longer (ORR4) and PFS. Both ORR4 and PFS strongly favored BV, with ORR4 of 56 versus $13 \%(P<0.0001)$ and median PFS of 16.7 versus 3.5 months (HR $0.27, P<0.0001$ ), with a median follow-up of 17.5 months. $^{87}$

Expanding the treatment spectrum, Jacobsen et al. reported an ORR of $44 \%$ in a phase II trial of BV in relapsed refractory B-cell lymphoma, including a majority cohort with diffuse large B-cell lymphoma (49 of 68 patients). Eight patients attained CR, with median response duration of 16.6 months. Median PFS was four months $\left(0.6+-24+\right.$ months) ${ }^{21}$ Bartlett et al. reported on the use of $B V$ in a cohort of 52 diffuse large B-cell lymphoma patients designated CD30 negative with conventional IHC, with an ORR of $31 \%$ and CR rate of $12 \%$. With computer-assisted digital image analysis, 11 of 16 responders were designated as low level positive for $\mathrm{CD} 30(\mathrm{CD} 30 \geqslant 1 \%)^{88}$

Brentuximab vedotin - additional treatment options. Bartlett et al. demonstrated that retreatment is feasible, treating 21 patients with $\mathrm{HL}$ and eight with $\mathrm{ALCL}$ who had previously achieved at least PR to BV. Overall response rate was $60 \%$ in the $\mathrm{HL}$ cohort and $88 \%$ in the ALCL cohort, with CR rates of 30 and $63 \%$, respectively. As expected, sensory and motor neuropathy rates were higher than in upfront treatment, but the regimen was otherwise well tolerated. $^{89}$

As with other antibody therapies, the next logical step was to use BV in combination. The use of BV with ABVD or AVD for upfront treatment of $\mathrm{HL}$ demonstrated significant additive pulmonary toxicity in the bleomycin-exposed cohort. Subsequent withdrawal of the bleomycin from the combination regimen did not appear to compromise efficacy. ${ }^{90}$ The phase III trial comparing ABVD and AVD with BV has completed recruitment; however, final results are pending. Promising results have been reported in a phase I trial in CD30-positive PTCL, using either BV administered sequentially with $\mathrm{CHOP}$, or BV in combination with $\mathrm{CHP}$. ORR was $85 \%$ in the sequential treatment arm, and $100 \%$ in the combination arm, with CR rates of 62 and $88 \%$, respectively. ${ }^{91}$ Additionally, early reports of a phase I/II trial of BV and bendamustine in patients with relapsed $\mathrm{HL}$ or $\mathrm{ALCL}$ suggest the combination is well tolerated, with an ORR of $67 \% .^{92}$

Other treatment options include the use of BV as consolidation rather than salvage. Moskowitz et al. reported on their doubleblind, randomized controlled trial assessing BV consolidation after auSCT for patients with relapsed HL. There was a significant improvement in risk of progression in the BV-treated cohort, with 


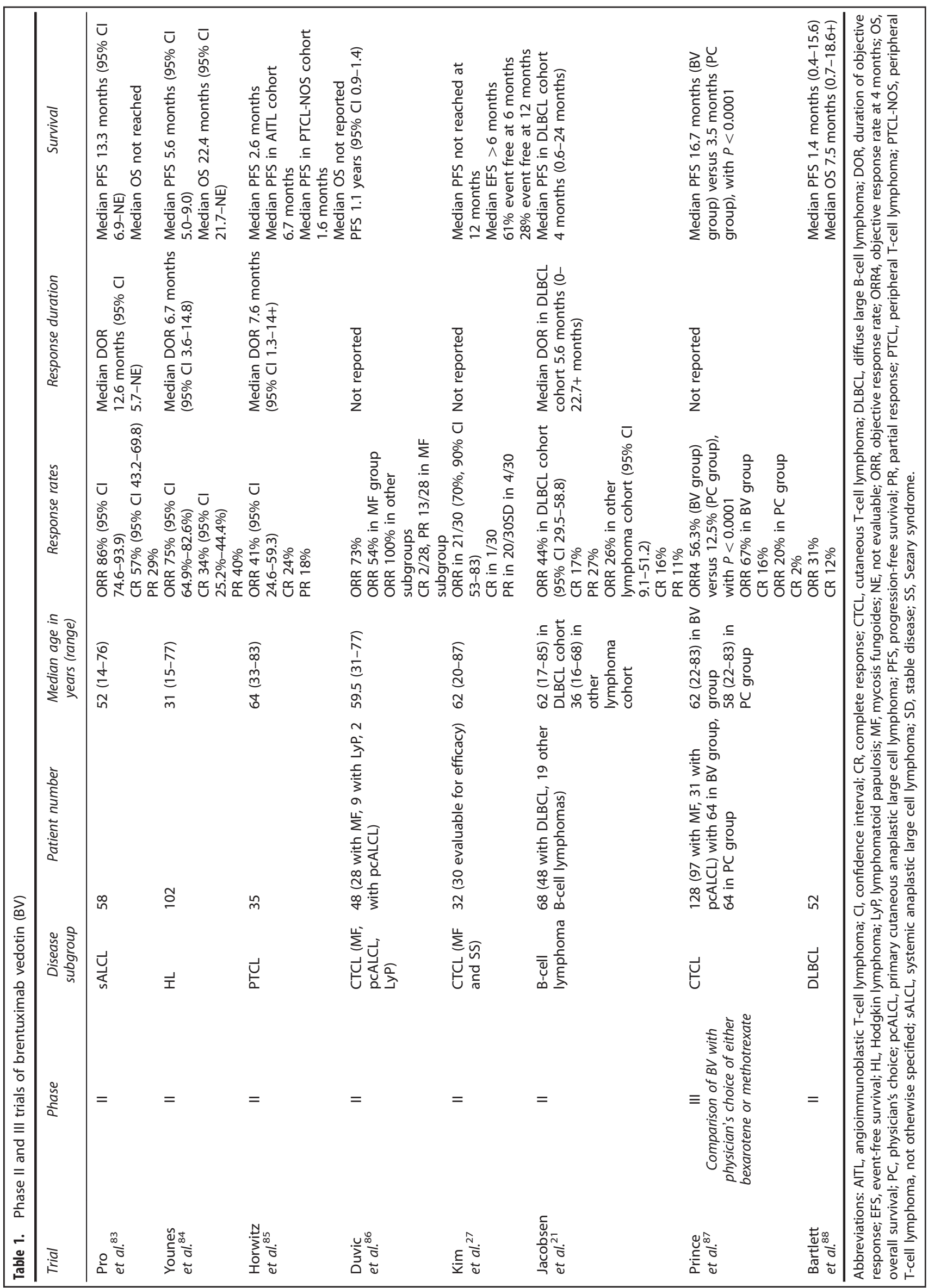


a median PFS of 42.9 months compared to 24.9 months in the placebo-treated cohort. By independent review, the estimated 2year PFS was $63 \%$ in the BV cohort and $51 \%$ in the placebo group. There was, however, no significant difference in overall survival between BV and placebo arms. ${ }^{93}$

The results of these studies raise some interesting questions, one of which is whether the efficacy of BV lies solely in its capacity to affect directed cell death. This does not seem to be the case, with evidence of enhanced T-cell activation as well as dendritic cell priming and maturation in mouse models treated with microtubule-depolymerizing agents akin to that in BV. ${ }^{81}$ In this context, the combination of BV with immune checkpoint inhibitors is a rational one, and indeed, has been the focus of a recent phase I/II trial. The other question is whether the predicted efficacy of BV can be stratified according to the level of CD30 positivity-and consequently, given the observed responses in patients nominally designated as low-level positive or even negative by IHC techniques, whether we need to reassess the way in which CD30 positivity is defined in the laboratory.

Brentuximab vedotin-side effects and resistance. While BV is undoubtedly more effective than naked mAbs and other conjugate therapies, it does not entirely overcome the problems seen with earlier immunotoxin compounds. Despite the documented cellular specificity of BV, the recognition of dose-limiting and cumulative peripheral neuropathy with treatment suggests the compound has off-target effects. This is likely mediated in part through the anti-tubulin effects of MMAE. ${ }^{79}$ Hansen et al. have recently shown that $\mathrm{HL}$ cells can release $\mathrm{CD} 30$-containing extracellular vesicles. These vesicles then bind to CD30Lexpressing cells in the tumor microenvironment, subsequently causing off-target binding of SGN-35 in vitro. ${ }^{94}$

In addition to the side effects reported in the major studies, subsequent case series have highlighted some concerning BV toxicities. Cases of pancreatitis-fatal at least one instance-have been reported. ${ }^{95}$ Progressive multifocal leukoencephalopathy, an incurable and often fatal CNS infection, has also been reported associated with BV. ${ }^{96}$

Resistance can be an issue with repeated BV exposure. Chen et al. have demonstrated diverse resistance mechanisms in $\mathrm{HL}$ and $A L C L$ cell lines, including increased expression of drug transporter proteins, and MMAE resistance. While CD30 downregulation is a putative mechanism, and was seen in vitro, this finding was not seen in the tissue samples examined in this study, ${ }^{97}$ mirroring prior case reports of persistent CD30 expression even in the setting of reduced BV efficacy. ${ }^{98}$ However, cases of relapsed/ refractory $A L C L$ with downregulation of $C D 30$ following $B V$ treatment have also been reported. ${ }^{99-101}$

\section{Other therapeutic approaches}

Phase I and II trials have been performed using bi-specific molecules incorporating anti-CD30 mAbs; however, the utility of these molecules has been hampered by the invariable development of antibodies against the agents. One such molecule combined an anti-CD30 mAb with the bi-specific mAb HRS-3/A9, directed against CD16, aiming to enhance recruitment of natural killer cells and phagocytic cells. A phase I/II clinical trial was conducted in 15 patients with relapsed/ refractory $\mathrm{HL}$, with one $\mathrm{CR}$ and one PR lasting six and three months respectively. Nine of the 15 patients developed antibodies to the bi-specific molecule, leading to treatment discontinuation. ${ }^{102}$

Similarly, an anti-CD64/anti-CD30 molecule H22 x Ki-4 was developed in the late 1990s. This combined the antigen-binding region of $\mathrm{Ki}-4$ with a humanized $\mathrm{CD} 64$-specific $\mathrm{mAb}$, with the theoretical rationale being that $\mathrm{CD} 64$, as part of the high affinity immunoglobulin receptor, should enhance antibody-dependent cell-mediated cytotoxicity. While it was well-tolerated in a phase I trial, with objective responses in four of 10 patients with multiply relapsed/ refractory $\mathrm{HL}$, interest in these agents has waned. ${ }^{103}$

The most recent efforts in targeting CD30 have focused on the use of chimeric antigen receptor T (CAR T) cells. Hombach et al. reported on the safety of CD30-specific CAR T therapy, demonstrating in mouse models that CD30/CD34-positive normal hematopoietic cells and activated lymphocytes were not targeted by CD30 CAR T cells. ${ }^{104}$ More importantly, Wang et al. have recently published preliminary results for a phase I trial, showing safety and efficacy, with PR in seven of the 18 patients treated, and stable disease in six. ${ }^{105}$

\section{FUTURE DIRECTIONS}

We are yet to fully define the significance of tumoral CD30 expression, that is, whether the molecule merely signifies cell of origin, for example, 'stimulated lymphocyte', whether its expression plays some role in perpetuating a malignant phenotype, or whether it reflects the recruitment of an inflammatory milieu that enhances tumor growth and survival. Indeed, CD30 expression may reflect a combination of all of these possibilities, and the relative balance of each may inform our thinking about tumor pathogenesis as well as how best to target CD30 therapeutically. Certainly it seems that merely demonstrating CD30 expression does not guarantee responses to anti-CD30 therapies, as demonstrated by the disappointing results of BV in PTCL-NOS, and the recently reported failure to achieve the ORR endpoint in a phase II study of BV in primary mediastinal B-cell lymphoma, despite strong CD30 expression in this tumor type. ${ }^{106}$ Conversely, the efficacy of BV in some tumors even with low-level CD30 expression is intriguing, suggestive of off-target immune modulatory effects of the compound, as discussed earlier.

The pleiotropic responses to CD30 stimulation are additionally of interest. Some of the studies outlined earlier would suggest the variable responses reflect differing mechanisms by which CD30 is upregulated in different tumor types, with consequent diverse effects on the signaling pathways mediated through CD30. The unanswered question is whether varying the type or mechanism of CD30 ligand binding may allow us to specifically target proapoptotic cellular signaling pathways, or to counteract cellular survival mechanisms. The finding that apoptosis may be augmented with antibody cross-linkage suggests this might be the case; however, this has not been studied in depth.

From a therapeutic standpoint, the failure to achieve substantive benefits with monoclonal antibodies and other antibodydrug combinations is disappointing. It is clear that BV overcomes many of these issues; however, the neurotoxicity of the MMAE may limit its long-term use. This raises the issue of why 'naked' antibody therapies are not as successful as expected. Some possibilities have been addressed, for example, it does not appear to be due to an excess of antibody binding to soluble CD30. ${ }^{107}$ The paucity of available structural data limits our understanding of the way in which CD30-antibody interactions occur, such as the possibility that the interaction between $\mathrm{CD} 30$ and anti-CD30 antibodies may orient the antibody in a way that is unable to properly induce antibody-dependent cell-mediated cytotoxicity. $\mathrm{X}$-ray or cryo-electron microscopy assessment of the structure of CD30 alone, CD30 in complex with CD30L, and CD30 bound to SGN-30 and SGN-35, would be invaluable in investigating these possibilities.

It has additionally been suggested that the differential response to anti-CD30 antibodies in HL and ALCL may in fact reflect a prosurvival benefit conferred by, and specific to, the $\mathrm{HL}$ microenvironment. ${ }^{64,108,109}$ Supporting this postulate is the observation of a 'bystander' effect on surrounding, non-CD30positive cells exposed to BV, which may alter the microenvironment immune signaling in HL. ${ }^{81,94}$ Clinical trials of the combination of nivolumab and BV are currently under way, with 
preliminary results suggesting that the combination is safe and well-tolerated. ${ }^{110}$ Trials combining the naked antibody with immune-checkpoint inhibitors would be an interesting question for future study.

Some of the therapeutic approaches targeting CD30 currently under investigation in clinical trials are summarized in Table 2. These trials are focused predominantly around the use of BV in combination with other agents, or exploring other therapeutic niches for BV, such as salvage as a bridge to transplant. Of note, however, is the use of anti-CD30 chimeric antigen receptor T cells, the results of which are awaited with interest.

The limited expression of CD30 to certain tumor types remains a tantalizing target in an era of purpose-designed therapies. Historical attempts at targeting CD30 may have failed due to a lack of clear understanding of the mechanisms and significance of CD30 expression in both health and in disease. Answering the question of how to maximize an anti-CD30 strategy into the future may require us to return to the laboratory bench, using contemporary structural techniques, molecular profiling and immunological modeling.

\section{CONFLICT OF INTEREST}

SAP is a member of the speaker bureau for Takeda Pharmaceutical Company and Seattle Genetics. HMP is an Advisory Board Member and has received research support from Takeda Pharmaceutical Company. The remaining authors declare no conflict of interest.

\section{REFERENCES}

1 Schwab U, Stein $\mathrm{H}$, Gerdes J, Lemke $\mathrm{H}$, Kirchner $\mathrm{H}$, Schaadt $\mathrm{M}$ et al. Production of a monoclonal antibody specific for Hodgkin and Sternberg-Reed cells of Hodgkin's disease and a subset of normal lymphoid cells. Nature 1982; 299: 65-67.

2 Stein H, Gerdes J, Schwab U, Lemke H, Mason DY, Ziegler A et al. Identification of Hodgkin and Sternberg-reed cells as a unique cell type derived from a newly-detected small-cell population. Int J Cancer 1982; 30: 445-459.

3 Durkop H, Latza U, Hummel M, Eitelbach F, Seed B, Stein H. Molecular cloning and expression of a new member of the nerve growth factor receptor family that is characteristic for Hodgkin's disease. Cell 1992; 68: 421-427.

4 Smith CA, Gruss HJ, Davis T, Anderson D, Farrah T, Baker E et al. CD30 antigen, a marker for Hodgkin's lymphoma, is a receptor whose ligand defines an emerging family of cytokines with homology to TNF. Cell 1993; 73: 1349-1360.

5 Smith CA, Farrah T, Goodwin RG. The TNF receptor superfamily of cellular and viral proteins: activation, costimulation, and death. Cell 1994; 76: 959-962.

6 Dong L, Hulsmeyer M, Durkop H, Hansen HP, Schneider-Mergener J, Ziegler A et al. Human CD30: structural implications from epitope mapping and modeling studies. J Mol Recognit 2003; 16: 28-36.

7 Mukai Y, Nakamura T, Yoshikawa M, Yoshioka Y, Tsunoda S, Nakagawa S et al. Solution of the structure of the TNF-TNFR2 complex. Sci Signal 2010; 3 ra83.

8 Gruss HJ, DaSilva N, Hu ZB, Uphoff CC, Goodwin RG, Drexler HG. Expression and regulation of $\mathrm{CD} 30$ ligand and $\mathrm{CD} 30$ in human leukemia-lymphoma cell lines. Leukemia 1994; 8: 2083-2094.

9 Younes A, Consoli U, Zhao S, Snell V, Thomas E, Gruss HJ et al. CD30 ligand is expressed on resting normal and malignant human $\mathrm{B}$ lymphocytes. $\mathrm{Br} J$ Haematol 1996; 93: 569-571.

10 Gruss HJ, Pinto A, Gloghini A, Wehnes E, Wright B, Boiani N et al. CD30 ligand expression in nonmalignant and Hodgkin's disease-involved lymphoid tissues. Am J Pathol 1996; 149: 469-481.

$11 \mathrm{Hsu}$ PL, Hsu SM. Autocrine growth regulation of CD30 ligand in CD30-expressing Reed-Sternberg cells: distinction between Hodgkin's disease and anaplastic large cell lymphoma. Lab Invest 2000; 80: 1111-1119.

12 Gattei V, Degan M, Gloghini A, De luliis A, Improta S, Rossi FM et al. CD30 ligand is frequently expressed in human hematopoietic malignancies of myeloid and lymphoid origin. Blood 1997; 89: 2048-2059.

13 Josimovic-Alasevic O, Durkop H, Schwarting R, Backe E, Stein H, Diamantstein T. $\mathrm{Ki}-1$ (CD30) antigen is released by Ki-1-positive tumor cells in vitro and in vivo. I. Partial characterization of soluble Ki-1 antigen and detection of the antigen in cell culture supernatants and in serum by an enzyme-linked immunosorbent assay. Eur J Immunol 1989; 19: 157-162.

14 Stein H, Mason DY, Gerdes J, O'Connor N, Wainscoat J, Pallesen G et al. The expression of the Hodgkin's disease associated antigen $\mathrm{Ki}-1$ in reactive and 
neoplastic lymphoid tissue: evidence that Reed-Sternberg cells and histiocytic malignancies are derived from activated lymphoid cells. Blood 1985; 66: 848-858.

15 Durkop H, Foss HD, Eitelbach F, Anagnostopoulos I, Latza U, Pileri S et al. Expression of the CD30 antigen in non-lymphoid tissues and cells. J Pathol 2000; 190: 613-618.

16 Beverley PC. Activation antigens: new and previously defined clusters. In: McMichael AJ (ed). Leucocyte Typing III. Oxford University Press; Oxford, 1987. pp 516-528.

17 Schwarting R, Gerdes J, Durkop H, Falini B, Pileri S, Stein H. BER-H2: a new anti-Ki1 (CD30) monoclonal antibody directed at a formol-resistant epitope. Blood 1989; 74: 1678-1689.

18 Ellis TM, Simms PE, Slivnick DJ, Jack HM, Fisher RI. CD30 is a signal-transducing molecule that defines a subset of human activated CD45RO+ T cells. J Immunol 1993; 151: 2380-2389.

19 Savage KJ, Harris NL, Vose JM, Ullrich F, Jaffe ES, Connors JM et al. ALKanaplastic large-cell lymphoma is clinically and immunophenotypically different from both ALK+ ALCL and peripheral T-cell lymphoma, not otherwise specified: report from the International Peripheral T-Cell Lymphoma Project. Blood 2008; 111: 5496-5504.

20 Kim WY, Nam SJ, Kim S, Kim TM, Heo DS, Kim CW et al. Prognostic implications of CD30 expression in extranodal natural killer/T-cell lymphoma according to treatment modalities. Leuk Lymphoma 2015; 56: 1778-1786.

21 Jacobsen ED, Sharman JP, Oki Y, Advani RH, Winter JN, Bello CM et al. Brentuximab vedotin demonstrates objective responses in a phase 2 study of relapsed/refractory DLBCL with variable CD30 expression. Blood 2015; 125: 1394-1402.

22 Montes-Moreno S, Odqvist L, Diaz-Perez JA, Lopez AB, de Villambrosia SG, Mazorra $\mathrm{F}$ et al. EBV-positive diffuse large B-cell lymphoma of the elderly is an aggressive post-germinal center B-cell neoplasm characterized by prominent nuclear factor-kB activation. Mod Pathol 2012; 25: 968-982.

23 Blatt K, Cerny-Reiterer S, Schwaab J, Sotlar K, Eisenwort G, Stefanzl G et al. Identification of the Ki-1 antigen (CD30) as a novel therapeutic target in systemic mastocytosis. Blood 2015; 126: 2832-2841.

24 Sotlar K, Cerny-Reiterer S, Petat-Dutter K, Hessel H, Berezowska S, Mullauer L et al. Aberrant expression of $\mathrm{CD} 30$ in neoplastic mast cells in high-grade mastocytosis. Mod Pathol 2011; 24: 585-595.

25 Bossard C, Dobay MP, Parrens M, Lamant L, Missiaglia E, Haioun C et al. Immunohistochemistry as a valuable tool to assess CD30 expression in peripheral T-cell lymphomas: high correlation with mRNA levels. Blood 2014; 124: 2983-2986.

26 Onaindia A, Martinez N, Montes-Moreno S, Almaraz C, Rodriguez-Pinilla SM, Cereceda $\mathrm{L}$ et al. CD30 expression by $\mathrm{B}$ and $\mathrm{T}$ cells: a frequent finding in angioimmunoblastic $\mathrm{t}$-cell lymphoma and peripheral $\mathrm{t}$-cell lymphoma-not otherwise specified. Am J Surg Pathol 2016; 40: 378-385.

27 Kim YH, Tavallaee M, Sundram U, Salva KA, Wood GS, Li S et al. Phase II investigator-initiated study of brentuximab vedotin in mycosis fungoides and sezary syndrome with variable CD30 expression level: a multi-institution collaborative project. J Clin Oncol 2015; 33: 3750-3758.

28 Edinger JT, Clark BZ, Pucevich BE, Geskin LJ, Swerdlow SH. CD30 expression and proliferative fraction in nontransformed mycosis fungoides. Am J Surg Pathol 2009; 33: 1860-1868.

29 Horie R, Watanabe T. CD30: expression and function in health and disease. Semin Immunol 1998; 10: 457-470.

30 Agrawal B, Reddish M, Longenecker BM. CD30 expression on human CD8+ $T$ cells isolated from peripheral blood lymphocytes of normal donors. $J$ Immunol 1996; 157: 3229-3234.

31 Manetti R, Annunziato F, Biagiotti R, Giudizi MG, Piccinni MP, Giannarini L et al. $\mathrm{CD} 30$ expression by $\mathrm{CD} 8+\mathrm{T}$ cells producing type 2 helper cytokines. Evidence for large numbers of CD8+CD30+ T cell clones in human immunodeficiency virus infection. J Exp Med 1994; 180: 2407-2411.

32 Del Prete G, De Carli M, D'Elios MM, Daniel KC, Almerigogna F, Alderson M et al. CD30-mediated signaling promotes the development of human Thelper type 2like T cells. J Exp Med 1995; 182: 1655-1661.

33 Hamann D, Hilkens CM, Grogan JL, Lens SM, Kapsenberg ML, Yazdanbakhsh M et al. CD30 expression does not discriminate between human Th1- and Th2-type T cells. J Immunol 1996; 156: 1387-1391.

34 Cattoretti G, Buttner M, Shaknovich R, Kremmer E, Alobeid B, Niedobitek G. Nuclear and cytoplasmic AID in extrafollicular and germinal center B cells. Blood 2006; 107: 3967-3975.

35 Cattoretti G, Shaknovich R, Smith PM, Jack HM, Murty VV, Alobeid B. Stages of germinal center transit are defined by $B$ cell transcription factor coexpression and relative abundance. J Immunol 2006; 177: 6930-6939.
36 Amakawa R, Hakem A, Kundig TM, Matsuyama T, Simard JJ, Timms E et al. Impaired negative selection of T cells in Hodgkin's disease antigen CD30deficient mice. Cell 1996; 84: 551-562.

37 Gaspal FM, Kim MY, McConnell FM, Raykundalia C, Bekiaris V, Lane PJ. Mice deficient in OX40 and CD30 signals lack memory antibody responses because of deficient CD4 T cell memory. J Immunol 2005; 174: 3891-3896.

38 Kennedy MK, Willis CR, Armitage RJ. Deciphering CD30 ligand biology and its role in humoral immunity. Immunology 2006; 118: 143-152.

39 Duckett CS, Thompson CB. CD30-dependent degradation of TRAF2: implications for negative regulation of TRAF signaling and the control of cell survival. Genes Dev 1997; 11: 2810-2821.

40 Schneider C, Hubinger G. Pleiotropic signal transduction mediated by human CD30: a member of the tumor necrosis factor receptor (TNFR) family. Leuk Lymphoma 2002; 43: 1355-1366.

41 Duckett CS, Gedrich RW, Gilfillan MC, Thompson CB. Induction of nuclear factor kappaB by the CD30 receptor is mediated by TRAF1 and TRAF2. Mol Cell Biol 1997; 17: 1535-1542.

42 Zheng B, Fiumara P, Li YV, Georgakis G, Snell V, Younes M et al. MEK/ERK pathway is aberrantly active in Hodgkin disease: a signaling pathway shared by CD30, CD40, and RANK that regulates cell proliferation and survival. Blood 2003; 102: 1019-1027.

43 Krysov SV, Rowley TF, Al-Shamkhani A. Inhibition of p38 mitogen-activated protein kinase unmasks a CD30-triggered apoptotic pathway in anaplastic large cell lymphoma cells. Mol Cancer Ther 2007; 6: 703-711.

44 Watanabe M, Nakano K, Togano T, Nakashima M, Higashihara M, Kadin ME et al. Targeted repression of overexpressed CD30 downregulates NF-kappaB and ERK1/2 pathway in Hodgkin lymphoma cell lines. Oncol Res 2011; 19: 463-469.

45 Buchan SL, Al-Shamkhani A. Distinct motifs in the intracellular domain of human CD30 differentially activate canonical and alternative transcription factor NFkappaB signaling. PLoS One 2012; 7: e45244.

46 Nishikori M, Ohno H, Haga H, Uchiyama T. Stimulation of CD30 in anaplastic large cell lymphoma leads to production of nuclear factor-kappaB p52, which is associated with hyperphosphorylated Bcl-3. Cancer Sci 2005; 96: 487-497.

47 Horie R, Watanabe T, Morishita Y, Ito K, Ishida T, Kanegae $\mathrm{Y}$ et al. Ligandindependent signaling by overexpressed CD30 drives NF-kappaB activation in Hodgkin-Reed-Sternberg cells. Oncogene 2002; 21: 2493-2503.

48 Hirsch B, Hummel M, Bentink S, Fouladi F, Spang R, Zollinger R et al. CD30induced signaling is absent in Hodgkin's cells but present in anaplastic large cell lymphoma cells. Am J Pathol 2008; 172: 510-520.

49 Watanabe M, Sasaki M, Itoh K, Higashihara M, Umezawa K, Kadin ME et al. JunB induced by constitutive CD30-extracellular signal-regulated kinase $1 / 2$ mitogenactivated protein kinase signaling activates the CD30 promoter in anaplastic large cell lymphoma and reed-sternberg cells of Hodgkin lymphoma. Cancer Res 2005; 65: 7628-7634.

50 Boddicker RL, Kip NS, Xing X, Zeng Y, Yang ZZ, Lee JH et al. The oncogenic transcription factor IRF4 is regulated by a novel CD30/NF-kappaB positive feedback loop in peripheral T-cell lymphoma. Blood 2015; 125: 3118-3127.

51 Pham-Ledard A, Prochazkova-Carlotti M, Laharanne E, Vergier B, Jouary T, BeylotBarry $M$ et al. IRF4 gene rearrangements define a subgroup of CD30-positive cutaneous T-cell lymphoma: a study of 54 cases. J Invest Dermatol 2010; 130: 816-825.

52 Watanabe M, Itoh K, Togano T, Kadin ME, Watanabe T, Higashihara M et al. Ets-1 activates overexpression of JunB and CD30 in Hodgkin's lymphoma and anaplastic large-cell lymphoma. Am J Pathol 2012; 180: 831-838.

53 Watanabe M, Ogawa Y, Ito K, Higashihara M, Kadin ME, Abraham LJ et al. AP-1 mediated relief of repressive activity of the CD30 promoter microsatellite in Hodgkin and Reed-Sternberg cells. Am J Pathol 2003; 163: 633-641.

54 Gruss HJ, Boiani N, Williams DE, Armitage RJ, Smith CA, Goodwin RG. Pleiotropic effects of the CD30 ligand on CD30-expressing cells and lymphoma cell lines. Blood 1994; 83: 2045-2056.

55 Wright CW, Rumble JM, Duckett CS. CD30 activates both the canonical and alternative NF-kappaB pathways in anaplastic large cell lymphoma cells. J Biol Chem 2007; 282: 10252-10262.

56 Mir SS, Richter BW, Duckett CS. Differential effects of CD30 activation in anaplastic large cell lymphoma and Hodgkin disease cells. Blood 2000; 96: 4307-4312.

57 Staber PB, Noehammer C, Durkop H, Schauer S, Kenner L, Linkesch W et al. mRNA expression patterns indicate CD30 mediated activation of different apoptosis pathways in anaplastic large cell lymphoma but not in Hodgkin's lymphoma. Leuk Res 2006; 30: 343-348.

58 Pfeifer W, Levi E, Petrogiannis-Haliotis T, Lehmann L, Wang Z, Kadin ME. A murine xenograft model for human CD30+ anaplastic large cell lymphoma. Successful growth inhibition with an anti-CD30 antibody (HeFi-1). Am J Pathol 1999; 155: 1353-1359. 
59 Tian ZG, Longo DL, Funakoshi S, Asai O, Ferris DK, Widmer M et al. In vivo antitumor effects of unconjugated CD30 monoclonal antibodies on human anaplastic large-cell lymphoma xenografts. Cancer Res 1995; 55: 5335-5341.

60 Maeda N, Muta H, Oflazoglu E, Yoshikai Y. Susceptibility of human T-cell leukemia virus type l-infected cells to humanized anti-CD30 monoclonal antibodies in vitro and in vivo. Cancer Sci 2010; 101: 224-230.

61 Wahl AF, Klussman K, Thompson JD, Chen JH, Francisco LV, Risdon G et al. The anti-CD30 monoclonal antibody $\mathrm{SGN}-30$ promotes growth arrest and DNA fragmentation in vitro and affects antitumor activity in models of Hodgkin's disease. Cancer Res 2002; 62: 3736-3742.

62 Cerveny CG, Law CL, McCormick RS, Lenox JS, Hamblett KJ, Westendorf LE et al. Signaling via the anti-CD30 mAb SGN-30 sensitizes Hodgkin's disease cells to conventional chemotherapeutics. Leukemia 2005; 19: 1648-1655.

63 Borchmann P, Treml JF, Hansen H, Gottstein C, Schnell R, Staak O et al. The human anti-CD30 antibody $5 \mathrm{~F} 11$ shows in vitro and in vivo activity against malignant lymphoma. Blood 2003; 102: 3737-3742.

64 Bartlett NL, Younes A, Carabasi MH, Forero A, Rosenblatt JD, Leonard JP et al. A phase 1 multidose study of SGN-30 immunotherapy in patients with refractory or recurrent CD30+ hematologic malignancies. Blood 2008; 111: 1848-1854.

65 Forero-Torres A, Leonard JP, Younes A, Rosenblatt JD, Brice P, Bartlett NL et al. A Phase II study of SGN-30 (anti-CD30 mAb) in Hodgkin lymphoma or systemic anaplastic large cell lymphoma. Br J Haematol 2009; 146: 171-179.

66 Duvic M, Reddy SA, Pinter-Brown L, Korman NJ, Zic J, Kennedy DA et al. A phase II study of SGN-30 in cutaneous anaplastic large cell lymphoma and related lymphoproliferative disorders. Clin Cancer Res 2009; 15: 6217-6224.

67 Ansell SM, Horwitz SM, Engert A, Khan KD, Lin T, Strair R et al. Phase I/II study of an anti-CD30 monoclonal antibody (MDX-060) in Hodgkin's lymphoma and anaplastic large-cell lymphoma. J Clin Oncol 2007; 25: 2764-2769.

68 Tazzari PL, Bolognesi A, de Totero D, Falini B, Lemoli RM, Soria MR et al. Ber-H2 (anti-CD30)-saporin immunotoxin: a new tool for the treatment of Hodgkin's disease and CD30+ lymphoma: in vitro evaluation. Br J Haematol 1992; 81: 203-211.

69 Pasqualucci L, Wasik M, Teicher BA, Flenghi L, Bolognesi A, Stirpe F et al. Antitumor activity of anti-CD30 immunotoxin (Ber-H2/saporin) in vitro and in severe combined immunodeficiency disease mice xenografted with human CD30+ anaplastic large-cell lymphoma. Blood 1995; 85: 2139-2146.

70 Terenzi A, Bolognesi A, Pasqualucci L, Flenghi L, Pileri S, Stein $\mathrm{H}$ et al. Anti-CD30 $(B E R=H 2)$ immunotoxins containing the type- 1 ribosome-inactivating proteins momordin and PAP-S (pokeweed antiviral protein from seeds) display powerful antitumour activity against CD30+ tumour cells in vitro and in SCID mice. Br J Haematol 1996; 92: 872-879.

71 Barth S, Huhn M, Matthey B, Tawadros S, Schnell R, Schinkothe T et al. Ki-4(scFv)ETA', a new recombinant anti-CD30 immunotoxin with highly specific cytotoxic activity against disseminated Hodgkin tumors in SCID mice. Blood 2000; 95: 3909-3914.

72 Matthey B, Borchmann P, Schnell R, Tawadros S, Lange $\mathrm{H}$, Huhn M et al. Metalloproteinase inhibition augments antitumor efficacy of the anti-CD30 immunotoxin $\mathrm{Ki}-3(\mathrm{scFv})-\mathrm{ETA}^{\prime}$ against human lymphomas in vivo. Int $J$ Cancer 2004; 111: 568-574.

73 Schnell R, Staak O, Borchmann P, Schwartz C, Matthey B, Hansen H et al. A Phase I study with an anti-CD30 ricin A-chain immunotoxin (Ki-4.dgA) in patients with refractory CD30+ Hodgkin's and non-Hodgkin's lymphoma. Clin Cancer Res 2002; 8: $1779-1786$.

74 Falini B, Bolognesi A, Flenghi L, Tazzari PL, Broe MK, Stein $\mathrm{H}$ et al. Response of refractory Hodgkin's disease to monoclonal anti-CD30 immunotoxin. Lancet 1992; 339: 1195-1196.

75 Schnell R, Dietlein M, Staak JO, Borchmann P, Schomaecker K, Fischer T et al. Treatment of refractory Hodgkin's lymphoma patients with an iodine-131labeled murine anti-CD30 monoclonal antibody. J Clin Oncol 2005; 23: 4669-4678.

76 Dietlein M, Borner SM, Fischer T, Hansen $\mathrm{H}$, Schnell R, Zimmermanns B et al. Development of anti-CD30 radioimmunoconstructs (RICs) for treatment of Hodgkin's lymphoma. Studies with cell lines and animal studies. Nuklearmedizin 2010; 49: 97-105.

77 Zhang M, Yao Z, Patel H, Garmestani K, Zhang Z, Talanov VS et al. Effective therapy of murine models of human leukemia and lymphoma with radiolabeled anti-CD30 antibody, HeFi-1. Proc Natl Acad Sci USA 2007; 104: 8444-8448.

78 Francisco JA, Cerveny CG, Meyer DL, Mixan BJ, Klussman K, Chace DF et al. CAC10-vcMMAE, an anti-CD30-monomethyl auristatin E conjugate with potent and selective antitumor activity. Blood 2003; 102: 1458-1465.

79 Okeley NM, Miyamoto JB, Zhang X, Sanderson RJ, Benjamin DR, Sievers EL et al. Intracellular activation of SGN-35, a potent anti-CD30 antibody-drug conjugate. Clin Cancer Res 2010; 16: 888-897.

80 Sutherland MS, Sanderson RJ, Gordon KA, Andreyka J, Cerveny CG, Yu C et al. Lysosomal trafficking and cysteine protease metabolism confer target-specific cytotoxicity by peptide-linked anti-CD30-auristatin conjugates. J Biol Chem 2006; 281: 10540-10547.

81 Muller P, Martin K, Theurich S, Schreiner J, Savic S, Terszowski G et al. Microtubule-depolymerizing agents used in antibody-drug conjugates induce antitumor immunity by stimulation of dendritic cells. Cancer Immunol Res 2014; 2: 741-755.

82 Younes A, Bartlett NL, Leonard JP, Kennedy DA, Lynch CM, Sievers EL et al. Brentuximab vedotin (SGN-35) for relapsed CD30-positive lymphomas. N Engl J Med 2010; 363: 1812-1821

83 Pro B, Advani R, Brice P, Bartlett NL, Rosenblatt JD, Illidge T et al. Brentuximab vedotin (SGN-35) in patients with relapsed or refractory systemic anaplastic large-cell lymphoma: results of a phase II study. J Clin Oncol 2012; 30: 2190-2196.

84 Younes A, Gopal AK, Smith SE, Ansell SM, Rosenblatt JD, Savage KJ et al. Results of a pivotal phase II study of brentuximab vedotin for patients with relapsed or refractory Hodgkin's lymphoma. J Clin Oncol 2012; 30: 2183-2189.

85 Horwitz SM, Advani RH, Bartlett NL, Jacobsen ED, Sharman JP, O'Connor OA et al. Objective responses in relapsed T-cell lymphomas with single-agent brentuximab vedotin. Blood 2014; 123: 3095-3100.

86 Duvic M, Tetzlaff MT, Gangar P, Clos AL, Sui D, Talpur R. Results of a Phase II trial of brentuximab vedotin for CD30+ cutaneous T-cell lymphoma and lymphomatoid papulosis. J Clin Oncol 2015; 33: 3759-3765.

87 Prince HM, Kim YH, Horwitz SM, Dummer R, Scarisbrick J, Quaglino D et al. Brentuximab vedotin or physician's choice in CD30-positive cutaneous T-cell lymphoma (ALCANZA): an international, open-label, randomised, phase 3 , multicentre trial. Lancet 2017; 390: 555-566.

88 Bartlett NL, Smith MR, Siddiqi T, Advani RH, O'Connor OA, Sharman JP et al. Brentuximab vedotin activity in diffuse large B-cell lymphoma with CD30 undetectable by visual assessment of conventional immunohistochemistry. Leuk Lymphoma 2017; 58: 1607-1616.

89 Bartlett NL, Chen R, Fanale MA, Brice P, Gopal A, Smith SE et al. Retreatment with brentuximab vedotin in patients with $\mathrm{CD} 30$-positive hematologic malignancies. J Hematol Oncol 2014; 7: 24

90 Oflazoglu E, Kissler KM, Sievers EL, Grewal IS, Gerber HP. Combination of the antiCD30-auristatin-E antibody-drug conjugate (SGN-35) with chemotherapy improves antitumour activity in Hodgkin lymphoma. Br J Haematol 2008; 142: 69-73.

91 Fanale MA, Horwitz SM, Forero-Torres A, Bartlett NL, Advani RH, Pro B et al. Brentuximab vedotin in the front-line treatment of patients with $\mathrm{CD} 30+$ peripheral T-cell lymphomas: results of a phase I study. J Clin Oncol 2014; 32: 3137-3143.

92 Sawas A CJ, Kuruvilla JG, Rojas C, Lichtenstein R, Neylon E, Lichtenstein E et al. The combination of brentuximab vedotin (Bv) and bendamustine (B) demonstrates marked activity in heavily treated patients with relapsed or refractory Hodgkin lymphoma $(\mathrm{HL})$ and anaplastic large T-cell lymphoma ( $\mathrm{ALCL}$ ): results of an international multi center phase I/ II experience. ASH Annual Meeting and Exposition; 5-8 December 2015; Orlando, FL.

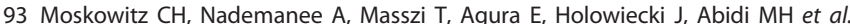
Brentuximab vedotin as consolidation therapy after autologous stem-cell transplantation in patients with Hodgkin's lymphoma at risk of relapse or progression (AETHERA): a randomised, double-blind, placebo-controlled, phase 3 trial. Lancet 2015; 385: 1853-1862.

94 Hansen HP, Trad A, Dams M, Zigrino P, Moss M, Tator M et al. CD30 on extracellular vesicles from malignant Hodgkin cells supports damaging of CD30 ligand-expressing bystander cells with Brentuximab-Vedotin, in vitro. Oncotarget 2016; 7: 30523-30535.

95 Gandhi MD, Evens AM, Fenske TS, Hamlin P, Coiffier B, Engert A et al. Pancreatitis in patients treated with brentuximab vedotin: a previously unrecognized serious adverse event. Blood 2014; 123: 2895-2897.

96 Carson KR, Newsome SD, Kim EJ, Wagner-Johnston ND, von Geldern G, Moskowitz $\mathrm{CH}$ et al. Progressive multifocal leukoencephalopathy associated with brentuximab vedotin therapy: a report of 5 cases from the Southern Network on Adverse Reactions (SONAR) project. Cancer 2014; 120: 2464-2471.

97 Chen R, Hou J, Newman E, Kim Y, Donohue C, Liu X et al. CD30 downregulation, MMAE resistance, and MDR1 upregulation are all associated with resistance to brentuximab vedotin. Mol Cancer Ther 2015; 14: 1376-1384.

98 Nathwani N, Krishnan AY, Huang Q, Kim Y, Karanes C, Smith EP et al. Persistence of CD30 expression in Hodgkin lymphoma following brentuximab vedotin (SGN-35) treatment failure. Leuk Lymphoma 2012; 53: 2051-2053.

99 Arai H, Furuichi S, Nakamura Y, Nakamura Y, Ichikawa M, Mitani K. ALK-negative anaplastic large cell lymphoma with loss of CD30 expression during treatment with brentuximab vedotin. Rinsho Ketsueki 2016; 57: 634-637. 
100 Nielson C, Fischer R, Fraga G, Aires D. Loss of CD30 expression in anaplastic large cell lymphoma following brentuximab therapy. J Drugs Dermatol 2016; 15: 894-895.

101 Al-Rohil RN, Torres-Cabala CA, Patel A, Tetzlaff MT, Ivan D, Nagarajan P et al. Loss of $C D 30$ expression after treatment with brentuximab vedotin in a patient with anaplastic large cell lymphoma: a novel finding. J Cutan Pathol 2016; 43: 1161-1166.

102 Hartmann F, Renner C, Jung W, Deisting C, Juwana M, Eichentopf B et al. Treatment of refractory Hodgkin's disease with an anti-CD16/CD30 bispecific antibody. Blood 1997; 89: 2042-2047.

103 Borchmann P, Schnell R, Fuss I, Manzke O, Davis T, Lewis LD et al. Phase 1 trial of the novel bispecific molecule H22xKi-4 in patients with refractory Hodgkin lymphoma. Blood 2002; 100: 3101-3107.

104 Hombach AA, Gorgens A, Chmielewski M, Murke F, Kimpel J, Giebel B et al. Superior therapeutic index in lymphoma therapy: CD30+ CD34+ hematopoietic stem cells resist a chimeric antigen receptor T-cell attack. Mol Ther 2016; 24: 1423-1434.

105 Wang CM, Wu ZQ, Wang Y, Guo YL, Dai HR, Wang XH et al. Autologous $T$ cells expressing CD30 chimeric antigen receptors for relapsed or refractory Hodgkin lymphoma: an open-label phase I trial. Clin Cancer Res 2017; 23: 1156-1166.

106 Zinzani PL, Pellegrini C, Chiappella A, Di Rocco A, Salvi F, Cabras MG et al. Brentuximab vedotin in relapsed primary mediastinal large B-cell lymphoma: results from a phase 2 clinical trial. Blood 2017; 129: 2328-2330.
107 Nagata S, Ise T, Onda M, Nakamura K, Ho M, Raubitschek A et al. Cell membranespecific epitopes on CD30: Potentially superior targets for immunotherapy. Proc Natl Acad Sci USA 2005; 102: 7946-7951.

108 Aldinucci D, Gloghini A, Pinto A, De Filippi R, Carbone A. The classical Hodgkin's lymphoma microenvironment and its role in promoting tumour growth and immune escape. J Pathol 2010; 221: 248-263.

109 Poppema S, van den Berg A. Interaction between host T cells and Reed-Sternberg cells in Hodgkin lymphomas. Semin Cancer Biol 2000; 10: 345-350.

110 Herrera AF, Bartlett NL, Ramchandren R, Vose JM, Moskowitz AJ, Feldman TA et al. Preliminary results from a phase $1 / 2$ study of brentuximab vedotin in combination with nivolumab in patients with relapsed or refractory Hodgkin lymphoma. Blood 2016; 128: 1105

This work is licensed under a Creative Commons Attribution 4.0 International License. The images or other third party material in this article are included in the article's Creative Commons license, unless indicated otherwise in the credit line; if the material is not included under the Creative Commons license, users will need to obtain permission from the license holder to reproduce the material. To view a copy of this license, visit http://creativecommons.org/licenses/ by/4.0/

(c) The Author(s) 2017 